\title{
Scarf and Akin Osteotomies for Correction of Hallux Abducto Valgus. A Ten- year Retrospective Patient Evaluation From Five Podiatric Surgery Centres Using PASCOM PSQ-10.
}

Sharon Clee ( $\nabla$ sharon.clee@nottshc.nhs.uk)

Nottinghamshire Healthcare NHS Foundation Trust

George Flanagan

Northamptonshire Healthcare NHS Trust: Northamptonshire Healthcare NHS Foundation Trust

Julian Pavier

Nottinghamshire Healthcare NHS Foundation Trust

lan Reilly

Northamptonshire Healthcare NHS Foundation Trust https://orcid.org/0000-0002-2786-5739

\section{Research}

Keywords: Hallux valgus, Scarf osteotomy, Akin osteotomy, surgery outcomes, service evaluation, PASCOM, PSQ-10

Posted Date: November 30th, 2021

DOI: https://doi.org/10.21203/rs.3.rs-1108625/v1

License: (c) (1) This work is licensed under a Creative Commons Attribution 4.0 International License. Read Full License 


\section{Abstract}

Background

Corrective surgery for hallux abducto valgus is one of the most commonly performed elective procedures in foot and ankle practice, with over a hundred different surgical solutions having been proposed throughout the literature. The purpose of the study was to identify the clinical and patient reported outcomes following Scarf-Akin osteotomies from five podiatric surgery centres over a ten-year period.

Method

This is a retrospective review from five podiatric surgical units which looked at patients who underwent Scarf osteotomies (in isolation or in combination with Akin procedures) over a ten-year period. Data was collected from the patient satisfaction questionnaires of the PASCOM-10 audit tool, which were completed by the patient six months post operatively, and further analysed using Microsoft Excel spreadsheet software.

Results

A total of 1351 patients were recorded undergoing Scarf (with or without an Akin) osteotomy for hallux abducto valgus, with 1227 females (90.83\%) and 124 males $(9.17 \%)$ identified but with only 1189 who had completed the patient satisfaction questionnaire. $96.8 \%$ of patients felt that their foot was either 'better' or 'much better' following surgery and that their original expectations of surgery had been met. Over $75 \%$ of patients had no post-operative sequalae identified, with metatarsal fracture noted to be the highest sequalae at $4.8 \%$.

\section{Conclusion}

From the five podiatric surgery units reviewed, Scarf osteotomies (with or without an Akin osteotomy) for hallux abducto valgus correction, have a high level of patient satisfaction with low post-operative sequalae.

Level of clinical evidence

IV (retrospective review).

\section{Introduction}

Hallux abducto valgus (HAV), or bunion deformity, is one of the most common presentations in foot and ankle practice [1, 2]. It is a complicated multiplanar pathology and is characterised by lateral deviation and valgus rotation of the hallux and medial deviation of the first metatarsal [1, 3, 4]. It has been reported that approximately $23 \%$ of adults aged between 18 and 65 years have the deformity which increases to $35.7 \%$ of the population above 65 years of age [3]. It has a higher female predilection and can often result in a decreased quality of life [5]. HAV is often intractable despite conservative care, ultimately requiring a surgical correction after a failure of conservative care [1, 2]. Over a hundred different surgical solutions have been proposed throughout the literature [6, 7]. Schrier et al [8] suggested that up to a third of patients operated on for HAV may be dissatisfied with the outcome of their surgery (though the paper they attribute this value to in fact demonstrated good patient outcomes). Nonetheless, patient reported outcomes are now crucial in capturing and evaluating treatment effectiveness.

The aim of the study was to collate post-operative sequalae from patients undergoing a common podiatric surgical procedure, over a large geographical area in the United Kingdom (UK), from five different surgical units in both the public and private sectors. This will highlight the overall satisfaction and complication rate and allow the authors to highlight common themes to aid the consenting process for future patients.

\section{Bunion surgery using the Scarf (+/- Akin) osteotomy}

Although no single surgical procedure has shown superiority, the Scarf osteotomy is a popular choice in HAV correction due to its versatility in treating mild, moderate and even severe HAV deformity [9-13]. The 'Scarf' term is derived from a carpentry method where two pieces of wood are joined together with the long ends overlapping. This creates stability via a construct which can resist tension and compression forces [14]. The Scarf osteotomy was traditionally be performed via translation (see Figs. 1 and 2) or rotation of the osteotomy, the latter technique utilised for deformities with higher intermetatarsal angle (IMA) [15]. Lopez et al [7] went further to combine the translation and rotation procedures to form the trotation Scarf osteotomy (see Figs. 3 and 4) to address a higher IMA. The Scarf osteotomy is often undertaken alongside an Akin osteotomy (a phalangeal, closing wedge, osteotomy) to augment the hallux abductus component of the HAV deformity [16].

Fixation of the Scarf osteotomy may vary from surgeon to surgeon but most commonly, two points of internal fixation are used. In more recent years, cannulated compression screws have been used where AO cortical screws were the norm. Some surgeons choose to use a Kirschner wire and a screw as there chosen two points of fixation, e.g. Lopez et al [7]. The Akin osteotomy is fixed with a single threaded Kirschner wire, staple or screw, as the intact lateral hinge is utilised as the second point of fixation.

\section{PASCOM-10 and the PSQ-10}

Foot health outcome measurement tools can be used to improve service delivery by collating and evaluating parameters such as pain, foot function, footwear, and mobility [18]. The Podiatric Audit of Surgery and Clinical Outcome Measurement system (PASCOM) was developed by the College of Podiatry in 1997 with the updated PASCOM-10 introduced to the podiatric surgery profession in the UK in 2010 [19]. It provides a structured framework in which to collate and 
compare data relating to the characteristics, outcome, and patient experiences of foot surgery [20]. It is a web-based database of podiatric procedures and outcomes which allows for retrospective reviews [21].

PASCOM-10 has three domains with the first encompassing the surgical treatment, the second relating to post-operative sequelae with the final section housing the patient satisfaction questionnaire (PSQ-10), [18]. The PSQ-10 questionnaire has ten questions (see Appendix 1) with the first asking the patient, in their own words, about their expectations about their surgery. The following nine answers are scored with a maximum of 100 points. Higher scores are an indication of high levels of satisfaction, whilst a minimum score of zero indicates the opposite [18,20]. The PSQ-10 has not undegone formal validation, although it has reliably demonstrated that satisfaction rates have not change over time $[18,20]$.

In Northampton, consent for the recoding and use of PASCOM data is done capturing the following at a pre-surgery health questionnaire, completed by the patient:

\section{Section 12: Surgery Audit - helping us improve our clinical outcomes}

To the patient: I understand that the clinician wishes to maintain my data on PASCOM-10, a web-based surgery audit system (with high level password protection). This will be used for anonymised data regarding my treatment outcomes and PASCOM information is held within my patient records. The purpose for using this database is to monitor the results and benefits of my treatment. I understand that my data will be anonymised so that no personal information can be retrieved. I can view my electronic PASCOM-10 record if I wish. When my data is used in reports my name will not appear and I cannot be identified. I also consent to be contacted by the podiatric surgery department to take part in any future research or evaluation. If I decline this does not affect my normal rights to have treatment, nor will I be treated differently in any way.

I give my permission for my information to be used in this way:

Signature of patient/date

To use PASCOM-10 data for this review, permission was sought and given from the respective NHS Trust clinical governance departments.

\section{Methods}

\section{Search strategy}

For the literature review, a strategy was adopted that involved searching for research evidence on Scarf bunion surgery outcomes via three different sources:

1. Electronic databases - healthcare databases advanced search (HDAS),

2. Reference lists,

3. Google Scholar,

HDAS allowed access to the following databases which were considered the give the best chance of identifying appropriate sources:

- AMED (Allied and Complementary Medicine: 1985 - present),

- CINHAL (Cumulative Index to Nursing/Allied Health Literature: 1981 - present)

- EMBASE (Excerpta Medica Database: 1974 - present),

- MEDLINE (Medical Literature Analysis and Retrieval Online: 1946 - present).

Additionally, UK podiatric journals were hand-searched. Inclusion criteria or selected articles were:

- Hallux valgus

- Outcomes

- PASCOM/PSQ-10

Exclusion criteria were studies transcribed and translated from languages other than English.

\section{PASCOM data}

A retrospective review of patient outcomes was performed using surgical audit data generated by and extracted from the PASCOM-10 online database. PASCOM-10 files are created when a patient is listed for surgical intervention and data is collated using the surgical information, complications, satisfaction, and patient reported outcome measure (PROM) scores. Activity is entered by clinical or administrative staff on the day of surgery and then at a 6-month postsurgical review [22], at which point the PSQ-10 questionnaire is completed together with the recoding of any post-operative sequelae. If patients fail to attend the 6-month review, there is an option for the questionnaire to be emailed to the patient, but often these episodes are lost to follow up.

The database has a built-in reporting system which can identify the appropriate patients relevant to a specific line of enquiry. The raw data collected from PASCOM-10 reported for any Scarf procedure performed either on its own or in combination with an Akin osteotomy, with additional analysis performed using Microsoft Excel spreadsheet (Microsoft 365). Reports were assembled from dates between 01/01/2010 (the inception of the current, on-line iteration of PASCOM) and 31/12/2019. Data from 2020 was not included as there had been a significant reduction in services due to COVID-19. 
Five centres were included in the study which consisted of both NHS and private practices. No limitation was placed on surgeon: the NHS services are podiatric surgery training centres and the procedures were performed by podiatric consultants, podiatric registrars, or surgical trainees under direct consultant supervision.

Post-operatively, each centre varied only slightly in terms of the regimen for patient follow up. Patients were generally reviewed in clinic for an initial dressing at two weeks with the option of a further dressing review a week or fortnight later. Patients were then advised regarding rehabilitation exercises and return to activities before being reviewed six months following the original surgery.

\section{Results}

There was a total of 1351 patients with 1227 females (90.83\%) (average age 59.13, SD 13.51) and 124 males (9.17\%) (average age 59.43 SD 15.37) who had undergone a Scarf +/- Akin osteotomy. The greatest percentage of females who underwent surgery were in the $60-79$ age group accounting for $47.38 \%$ of the total cohort. Males in the same age range accounted for $5.10 \%$ of the population. The average outcome data score was 89.68 out of 100 (SD $+/-9.64$ ). Regrettably, not all episodes were fully captured on the PASCOM-10 database: 1189 (88\%) patients completed the PSQ-10 questionnaire but 162 were lost to follow up.

Table 1

Age demographics for patients

\begin{tabular}{|lllll|}
\hline Age & Male & Male \% & Female & Female \% \\
\hline $0-19$ & 1 & 0.07 & 0 & 0.00 \\
\hline $20-39$ & 15 & 1.11 & 131 & 9.70 \\
$40-59$ & 34 & 2.51 & 411 & 30.42 \\
\hline $60-79$ & 69 & 5.10 & 640 & 47.38 \\
\hline $80+$ & 5 & 0.37 & 45 & 3.33 \\
\hline Total & 124 & 9.16 & 1227 & 90.83 \\
\hline
\end{tabular}

Of those who did complete their PSQ-10, 1177 (98.9\%) patients identified their expectations for the surgery in Q1 of the questionnaire. The responses were collated into Microsoft Excel (Microsoft 365) which could then be arranged to four common themes. Some patients mentioned more than one expectation but a reduction in pain was the biggest goal for patients, followed by a better looking or straighter foot. Interestingly, only $12 \%$ of the patients who answered were looking for a return to sports or the ability to function better on their foot following their bunion correction. This may be partly due to the age demographics with over $74 \%$ of patients aged over 55 and perhaps less likely to partake in active sports. A summary of the PSQ-10 Q1 answers can be found in Table 2 .

Table 2

Responses from Q1 from PSQ-10 questionnaire - What do you expect to gain from treatment

\begin{tabular}{|lllll|}
\hline & No/less Pain & Better looking/ Straighter foot & Easier Footwear & Walking better / retum to sports \\
\hline Total responses & 819 & 303 & 295 & 143 \\
\hline$\%$ & $70 \%$ & $25.7 \%$ & $25 \%$ & $12 \%$ \\
\hline
\end{tabular}

Answers to Qs 2-10 (minus Q4) are listed in Table 3. 
A summary of the PSQ-10 questionnaire answers

\begin{tabular}{|c|c|c|c|}
\hline Question & Yes & No/not sure & Not stated \\
\hline 2. Were the risks and complications explained to you? & Yes $1171(98.5 \%)$ & $12(1 \%)$ & $6(0.5 \%)$ \\
\hline 3. Did you have a problem after surgery? & Yes $1171(98.5 \%)$ & $913(76.8 \%)$ & $7(0.6 \%)$ \\
\hline \multirow[t]{2}{*}{ 5. When could you get back into your shoes? } & Minor $225(18.9 \%)$ & & $7(0.6 \%)$ \\
\hline & Major $44(3.7 \%)$ & & \\
\hline \multirow[t]{6}{*}{ 6. Do you still have discomfort from your original foot condition? } & 2 weeks $209(17.6 \%)$ & $507(42.6 \%)$ & $8(0.7 \%)$ \\
\hline & 4 weeks $354(29.8 \%)$ & & \\
\hline & 6 weeks $294(24.7 \%)$ & & \\
\hline & 8 weeks $234(19.7 \%)$ & & \\
\hline & 12 weeks $46(3.9 \%)$ & & \\
\hline & $6+$ months $45(3.5 \%)$ & & \\
\hline \multirow[t]{4}{*}{ 7. How is your original foot condition? } & Occasional twinge 540 (45.4\%) & & $6(0.5 \%)$ \\
\hline & Standing long time 91 (7.7\%) & & \\
\hline & When standing $17(1.4 \%)$ & & \\
\hline & At rest $26(2.2 \%)$ & & \\
\hline \multirow[t]{5}{*}{ 8. Would you have surgery again under the same circumstances? } & Much better 950 (79.9\%) & $32(2.7 \%)$ & $9(0.8 \%)$ \\
\hline & Better $201(16.9 \%)$ & & \\
\hline & The same $21(1.8 \%)$ & & \\
\hline & A little worse $7(0.6 \%)$ & & \\
\hline & Deteriorated $4(0.3 \%)$ & & \\
\hline 9. Were the original expectations that you stated at the beginning met? & Yes $1148(96.6 \%)$ & $9(0.8 \%)$ & $6(0.5 \%)$ \\
\hline \multirow[t]{2}{*}{ 10. Were the original expectations that you stated at the beginning met? } & Yes $1103(92.8 \%)$ & $25(1.1 \%)$ & $12(0.5 \%)$ \\
\hline & In part $71(6.0 \%)$ & & \\
\hline
\end{tabular}

Post-operative complication data was gathered from the in-built reporting tool. 75.1\% (964 of the cohort) observed no sequalae. A detailed breakdown of postsurgical sequalae can be observed in Table 4. 
Table 4

Most frequently occurring post-operative sequalae

\begin{tabular}{|c|c|c|}
\hline Sequalae & Number $(n=2494)$ & $\%$ \\
\hline No observed sequalae & 964 & 75.1 \\
\hline Metatarsal fracture & 62 & 4.8 \\
\hline Joint pain \& stiffness $>3$ months & 53 & 4.1 \\
\hline Scar hypertrophy / keloid & 26 & 2.0 \\
\hline Swelling beyond 4 months & 25 & 1.9 \\
\hline Pain at surgical site $>6$ weeks & 23 & 1.8 \\
\hline Transfer metatarsalgia & 21 & 1.6 \\
\hline Fixation problems requiring removal & 20 & 1.5 \\
\hline Infection suspected / not proven & 18 & 1.4 \\
\hline Stitch abscess / suture reaction & 12 & 0.9 \\
\hline Wound dehiscence & 10 & 0.8 \\
\hline Surgery failed e.g. recurrence, hallux varus) & 9 & 0.7 \\
\hline Infection proven & 7 & 0.5 \\
\hline DVT & 7 & 0.5 \\
\hline Excessive post-operative pain (first 72 hours) & 5 & 0.4 \\
\hline Patient non-compliance & 5 & 0.4 \\
\hline Motor Power weakness & 3 & 0.2 \\
\hline Bone union delay & 2 & 0.2 \\
\hline Medication side effect & 1 & 0.1 \\
\hline Callus or IPK formation & 1 & 0.1 \\
\hline Haematoma & 1 & 0.1 \\
\hline
\end{tabular}

\section{Discussion}

PROMs are becoming an integral component of health care practice and they should encompass items that are relevant to the patient [23]. Baumhauer et al [24] showed that outcome factors regarded by patients as important for foot/ankle complaints differ from factors judged by physicians. It was the intention at the conceptual stage of the PSQ-10 questionnaire to capture and explore the patient's perception of their treatment [20] rather than assessing the outcome from a clinician's point of view. Maher and Tollafield [19] proposed that a PSQ-10 threshold score of 75 or above can be for isolated HAV correction. In their paper, they presented a mean PSQ-10 score of 86.5 for patients who underwent a Scarf osteotomy. The timing of obtaining a PROM is dependent on many variables [5]. Rudge \& Tollafield asked centres to send questionnaires to patients six months after surgery [20] but further work is being undertaken by the team to identify if PASCOM outcome scores change over time. The consensus within UK podiatric surgical units that PROMs have continued to be gathered at six month following treatment.

From our study we found that a total of 1151 patients ( $96.8 \%$ of the cohort) felt that their foot condition was either 'better' ( $16.9 \%)$ or 'much better' ( $79.9 \%$ ) following surgery. This is consistent with the findings of Crevoisier et al [25], and Spruce et al [26] who each identified that $94 \%$ of their cohort felt they had improved following a Scarf osteotomy. $86 \%$ of Crevoisier's cohort said they would undergo the same procedure again whilst Kerr et al [27] reported that only $74.3 \%$ of their patients who underwent a Scarf osteotomy would. These findings are lower than our results which showed $96.6 \%$ would proceed with surgery in the future. Importantly, over $92 \%$ of our patients felt that their expectations had been fully met following the Scarf osteotomy with only $6 \%$ of those answering feeling that they had been partly met. Less than $1 \%$ felt that their expectations for surgery had not been met following the surgical procedure.

Metatarsal fracture was the most common post-operative complication affecting $4.8 \%$ of our cohort and may reflect differences in the recording of sequela by the five units. Fracture was not shown to be a factor in the study performed by Lipscombe et al who only had two complications: a traumatic neuroma and avascular necrosis requiring an arthrodesis of the first metatarsophalangeal joint [28]. A midterm experience of scarf osteotomy by Samaras et al highlighted 15 out of 70 feet with complications which included 7 recurrences, one deep vein thrombosis (DVT), four cases of complex regional pain syndrome, 3 intraoperative fractures and 3 cases of failure of osteosynthesis [18]. Smith and colleagues [10] reported metatarsal fractures, but these were intraoperative in two cases whilst 2 stress fracture were seen at 3- and 7-months post operatively. They didn't however identify in which metatarsal the stress fractures occurred. Barouk observed $3 \%$ of his study to be at risk of metatarsal fracture [29]. Metatarsal troughing, delayed union, rotational malunion, recurrence of deformity and infection were all identified as post-operative complications following a Scarf osteotomy by Coetzee [15]. 
Joint pain and stiffness were recorded in 53 (4.1\%) of our study which is much less than that found by Crevoisier et al [25]. They found that first metatarsophalangeal joint motion worsened in $7 \%$ of their patients who underwent a Scarf osteotomy in isolation and in $6.7 \%$ of patients who underwent an additional Akin osteotomy [23]. Our analysis identified 26 patients (2\%) who acknowledged a problem with their scar at their six-month review which differs from leong et al who found that $31 \%$ of their patients had experienced symptoms at the scar site when they were reviewed at a minimum of 1 year post operatively [30].

There were no reported incidences of complex regional pain syndrome (CRPS) in this study, conversely, Samaras et al [11] and Deenik et al [31] noted rates of $5 \%$ and $10.6 \%$ respectively. 7 cases of DVT were highlighted in our study equating to $0.5 \%$ of the cohort. Samaras et al in 2019 documented only 1 case of DVT in their 70 patients undergoing a Scarf osteotomy. Their patients were noted to have been prescribed low molecular weight heparin (LMWH) for 3 weeks despite being allowed to immediately weight bear in a heel wedge shoe [18]. This seems to contradict the thoughts of Jameson et al [32] who suggested that patients in the U.K. undergoing bunion surgery had no clear risk factors for venous thromboembolism (VTE) and VTE prophylaxis had no benefit in ambulatory cases. Harrison and Walker [33] proposed that patients who are ambulatory after day case surgery were not considered to be at high risk of VTE and forefoot surgery should be considered low risk.

As with any audit and data collection, the results are only as good as the information inputted. Consequently, the post-operative sequalae shown in this study may be underestimated. Some post-operative dressings were performed by specialist nurses or health care assistants who may not have had access to the PASCOM-10 database and therefore under reporting incidences, such as stitch abscesses. Many of the complications are seen early in the post-operative phase whilst the main post-operative concerns are inputted at 6 months following surgery when the PSQ-10 questionnaire is completed. In the future it would be prudent to record all sequalae when they occur, rather than waiting until the final 6-month review.

Both NHS units are training centres for podiatric surgery trainees and registrars. It was not possible from the collated data to unpick whether the outcome varied between surgeon grades (and therefore by extrapolation, experience). This would be a useful area to unpick in future studies but would require separate data to be prospectively gathered using PASCOM.

\section{Conclusion}

Although the figures presented are mid-term results, the authors believe that the data gives a good indication of the outcomes and post-operative sequelae that may affect patients undergoing a Scarf (+/-Akin) osteotomy for HAV correction. This should enable a more informed consenting process with our patients in the future. The data suggests good outcomes for the procedure(s) in a wide cohort of patients, across five podiatric centres where much of the surgery is performed by non-consultant grades. This study has also highlighted the importance of inputting post-operative sequalae as they occur, rather than waiting until the final review, for a more accurate and comprehensive overview of any concerns raised by both patient and clinician.

\section{Declarations}

\section{Acknowledgments}

We wish to thank our patients who allow us to input their surgical outcome data into PASCOM, and to our respective NHS Trusts who support us in the recording and use of this data to monitor and improve patient outcomes.

\section{Declarations}

This research did not receive any grant from funding agencies in the public, commercial, or not-for-profit sectors. All authors have no competing interests to declare. Organisation ethical approval was not required.

IR conceived the aim and format of the paper. SC performed the literature search and produced the first draft. All authors made substantial contributions to the final version.

\section{References}

1. Matar HE, Platt SR. Overview of randomised controlled trials in hallux valgus surgery (2,184 patients). Foot and Ankle Surgery. 2020 May 22. https://doi.org/10.1016/j.fas.2020.04.013.

2. Chen L, Lyman S, Do H, Karlsson J, Adam SP, Young E, Deland JT, Ellis SJ. Validation of foot and ankle outcome score for hallux valgus. Foot \& Ankle International. 2012 Dec;33(12):1145-55. https://doi.org/10.3113/FAl.2012.1145.

3. Chong A, Nazarian N, Chandrananth J, Tacey M, Shepherd D, Tran P. Surgery for the correction of hallux valgus: minimum five-year results with a validated patient-reported outcome tool and regression analysis. The Bone \& Joint Journal. 2015 Feb;97(2):208-14. https://doi.org/10.1302/0301620X.97B2.34891.

4. Zhu M, Chen JY, Yeo NE, Koo K, Rikhraj IS. Health-related quality-of-life improvement after hallux valgus corrective surgery. Foot and Ankle Surgery. 2021 Jul 1;27(5):539-42. https://doi.org/10.1016/j.fas.2020.07.001.

5. Nix S, Smith M, Vicenzino B. Prevalence of hallux valgus in the general population: a systematic review and meta-analysis. Journal of Foot and Ankle Research. 2010 Dec;3(1):1-9. https://doi.org/10.1186/1757-1146-3-21. 
6. Matthews M, Klein E, Youssef A, Weil Jr L, Sorensen M, Weil Sr LS, Fleischer A. Correlation of radiographic measurements with patient-centered outcomes in hallux valgus surgery. Foot \& ankle international. 2018 Dec;39(12):1416-22. https://doi.org/10.1177/1071100718790255.

7. Lopez FM, Reilly I, Murphy L. The Scarf Osteotomy: A technique variant: The trotation scarf and Akin osteotomies for hallux valgus: Short term results of 73 cases. Foot Ankle Online Journal. 2015;8:3-12. https://doi.org,10.3827/faoj.2015.0801.0003

8. Schrier JC, Palmen LN, Verheyen CC, Jansen J, Koëter S. Patient-reported outcome measures in hallux valgus surgery. A review of literature. Foot and Ankle Surgery. 2015 Mar 1;21(1):11-5. https://doi.org/10.1016/j.fas.2014.11.004.

9. Castioni D, Fanelli D, Gasparini G, lannò B, Galasso O. Scarf osteotomy for the treatment of moderate to severe hallux valgus: analysis of predictors for midterm outcomes and recurrence. Foot and Ankle Surgery. 2020 Jun 1;26(4):439-44. https://doi.org/10.1016/j.fas.2019.05.013.

10. Smith AM, Alwan T, Davies MS. Perioperative complications of the Scarf osteotomy. Foot \& Ankle International. 2003 Mar;24(3):222-7. https://doi.org/10.1177/107110070302400304.

11. Samaras D, Gougoulias N, Varitimidis S, Hantes M, Karachalios T, Malizos K, Dailiana Z. Midterm experience of Scarf osteotomy as a new technique in a General Orthopaedic Department. The Foot. 2019 Sep 1;40:68-75. https://doi.org/10.1016/j.foot.2019.04.002.

12. Weil LS. Scarf osteotomy for correction of hallux valgus. Historical perspective, surgical technique, and results. Foot and Ankle Clinics. 2000 Sep 1;5(3):559-80. https://europepmc.org/article/med/11232397

13. Barouk LS. Scarf osteotomy of the first metatarsal in the treatment of hallux vulgus. Foot Diseases. 1995;2(1):35-48. https://ci.nii.ac.jp/naid/10014971921/.

14. Weil Jr L, Bowen M. Scarf osteotomy for correction of hallux abducto valgus deformity. Clinics in Podiatric Medicine and Surgery. 2014 Feb 26;31(2):23346. https://doi.org/10.1016/j.cpm.2013.12.005

15. Coetzee JC. Scarf osteotomy for hallux valgus repair: the dark side. Foot \& Ankle International. 2003 Jan;24(1):29-33. https://doi.org/10.1177/107110070302400104.

16. Rettedal D, Lowery NJ. Proximal phalangeal osteotomies for hallux abductovalgus deformity. Clinics in Podiatric Medicine and Surgery. 2014 Apr 1;31(2):213-20. https://doi.org/10.1016/j.cpm.2013.12.003.

17. Duke HF. Rotational scarf (Z) osteotomy bunionectomy for correction of high intermetatarsal angles. Journal of the American Podiatric Medical Association. 1992 Jul;82(7):352-60. https://doi.org/10.7547/87507315-82-7-352.

18. Taylor NG, Tollafield DR, Rees S. Does patient satisfaction with foot surgery change over time? The Foot. 2008 Jun 1;18(2):68-74. https://doi.org/10.1016/j.foot.2008.01.003.

19. Maher A, Tollafield D. Hallux valgus correction by metatarsal osteotomy PASCOM-10 Working Party. Podiatry Now. 2013 May:18-20. https://eastmid.openrepository.com/bitstream/handle/20.500.12904/5037/Maher\%202013\%2018-20.pdf? sequence=2.

20. Rudge G \& Tollafield DR. A critical assessment of a new evaluation tool for podiatric surgical outcome analysis. British Journal of Podiatry. November. 2003;6(4):109-19. https://www.semanticscholar.org/paper/A-critical-assessment-of-a-new-evaluation-tool-for-RudgeTollafield/0760aae3327f5fdca53dbdebd7181a7ca0903d5c.

21. Evans A, Chong J, Reilly I. Service Evaluation: A comparison of outcomes of first metatarsophalangeal joint arthrodesis in a community NHS Trust. Podiatry Now. 2017 Nov:11-15.

https://www.researchgate.net/publication/320621228_A_comparison_of_outcomes_of_first_metatarsophalangeal_joint_arthrodesis_in_a_community_NH:

22. Maher A. Service Evaluation, outcome measurement and PASCOM-10. A review of the literature. Podiatry Now. 2016 Dec:16-20. https://www.researchgate.net/publication/310828093_Service_evaluation_outcome_measurement_and_PASCOM-10.

23. MacDonald A, Houck J, Baumhauer JF. Role of patient-reported outcome measures on predicting outcome of bunion surgery. Foot \& Ankle International. 2020 Feb;41(2):133-9. https://doi.org/10.1177/107110071988628.

24. Baumhauer JF, Mclntosh S, Rechtine G. Age and sex differences between patient and physician-derived outcome measures in the foot and ankle. JBJS. 2013 Feb 6;95(3):209-14. https://doi.org/10.2106/JBJS.K.01467.

25. Crevoisier X, Mouhsine E, Ortolano V, Udin B, Dutoil M. The scarf osteotomy for the treatment of hallux valgus deformity: a review of 84 cases. Foot \& Ankle International. 2001 Dec;22(12):970-6. https://doi.org/10.1177/107110070102201208.

26. Spruce MC, Bowling FL, Metcalfe SA. A longitudinal study of hallux valgus surgical outcomes using a validated patient centred outcome measure. The Foot. 2011 Sep 1;21(3):133-7. https://doi:10.1016/j.foot.2011.01.012.

27. Kerr HL, Jackson R, Kothari P. Scarf-Akin osteotomy correction for hallux valgus: short-term results from a district general hospital. The Journal of Foot and Ankle Surgery. 2010 Jan 1;49(1):16-9. https://doi.org/10.1053/j.jfas.2009.07.024.

28. Lipscombe S, Molloy A, Sirikonda S, Hennessy MS. Scarf osteotomy for the correction of hallux valgus: midterm clinical outcome. The Journal of Foot and Ankle Surgery. 2008 Jul 1;47(4):273-7. https://doi.org/10.1053/j.jfas.2008.02.021

29. Barouk LS. Local Anatomy, Surgical Technique, and combination with other forefoot procedures. Foot and Ankle Clinics. 2000 Sep;5(3):525. https://pubmed.ncbi.nlm.nih.gov/11232396/.

30. leong E, Afolayan J, Little N, Solan M, Pearce C. The incidence and natural history of forefoot scar pain following open hallux valgus surgery. Foot \& Ankle Specialist. 2013 Aug;6(4):271-5. https://doi.org/10.1177/1938640013489344.

31. Deenik A, van Mameren H, de Visser E, de Waal Malefijt M, Draijer F, de Bie R. Equivalent correction in scarf and chevron osteotomy in moderate and severe hallux valgus: a randomized controlled trial. Foot \& Ankle International. 2008 Dec;29(12):1209-15. https://doi.org/10.3113/FAl.2008.1209.

32. Jameson SS, Augustine A, James P, Serrano-Pedraza I, Oliver K, Townshend D, Reed MR. Venous thromboembolic events following foot and ankle surgery in the English National Health Service. The Journal of Bone and Joint Surgery. British volume. 2011 Apr;93(4):490-7. https://doi.org/10.1302/0301- 
620X.93B4.25731.

33. Harrison WD, Walker CR. Controversies and trends in United Kingdom bunion surgery. Foot and Ankle Clinics. 2016 Jun 1;21(2):207-17. https://doi.org/10.1016/j.fcl.2016.01.001.

\section{Figures}

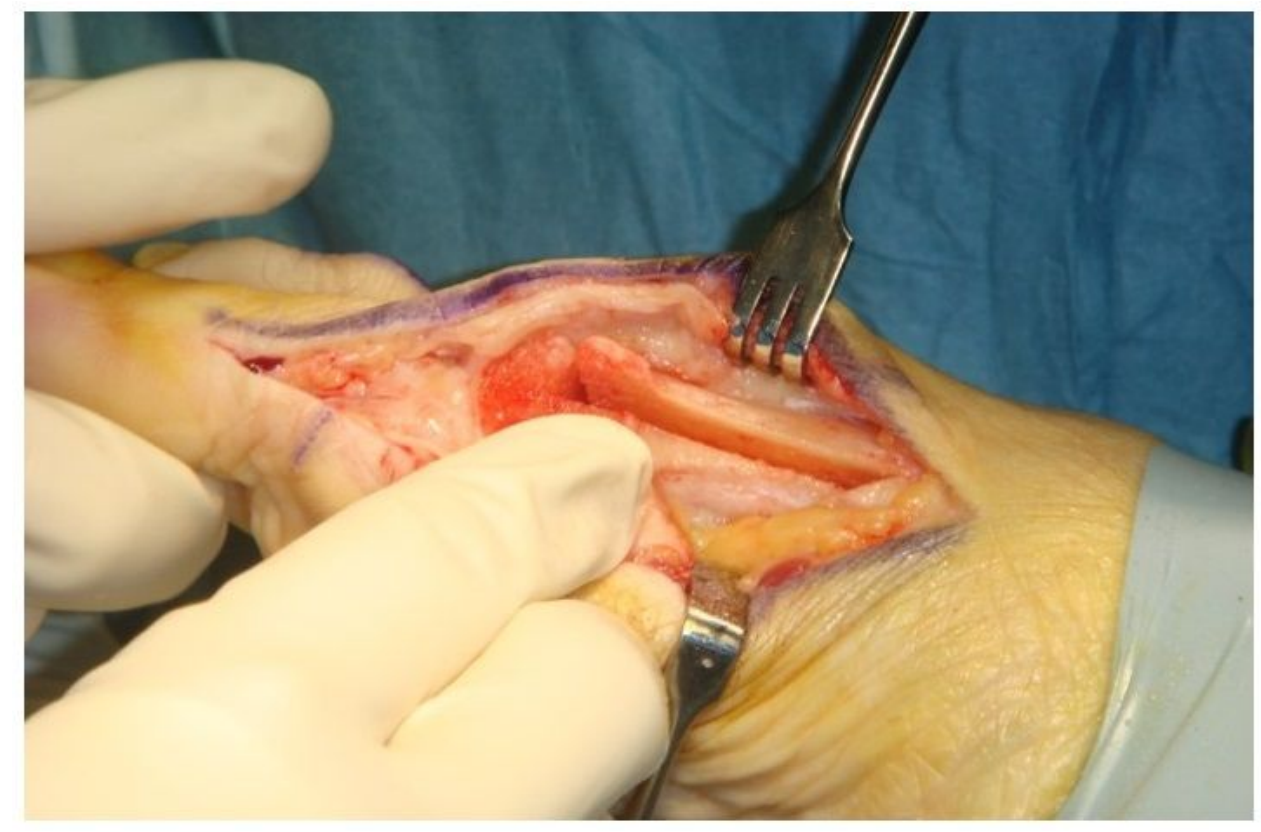

\section{Figure 1}

\section{translation Scarf}

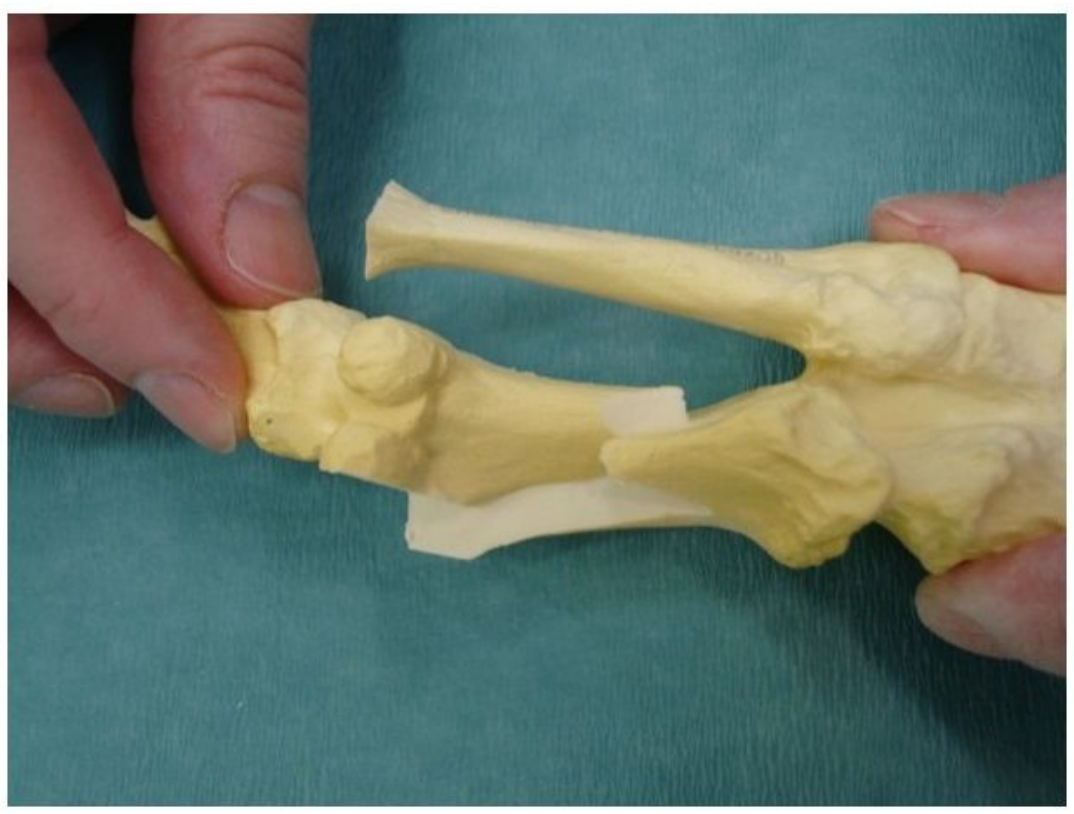

\section{Figure 2}

translation (saw bone) 


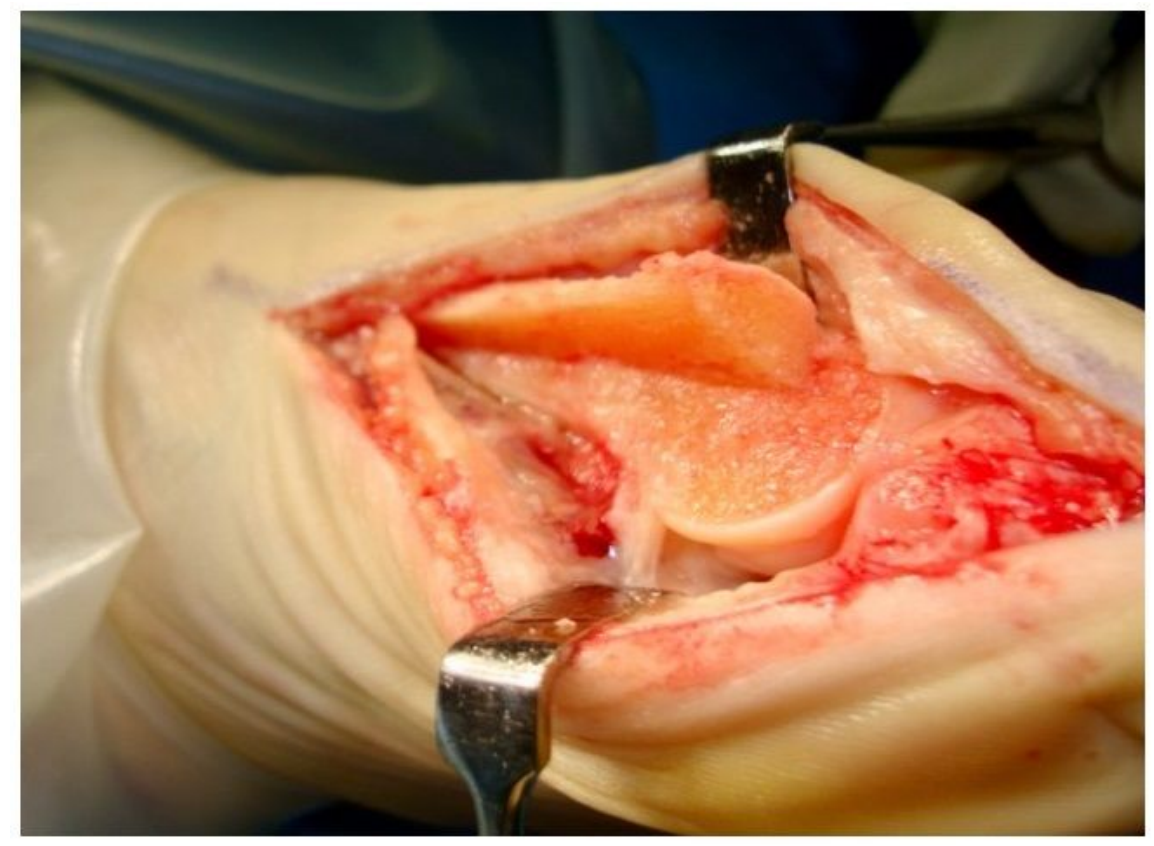

Figure 3

trotation Scarf

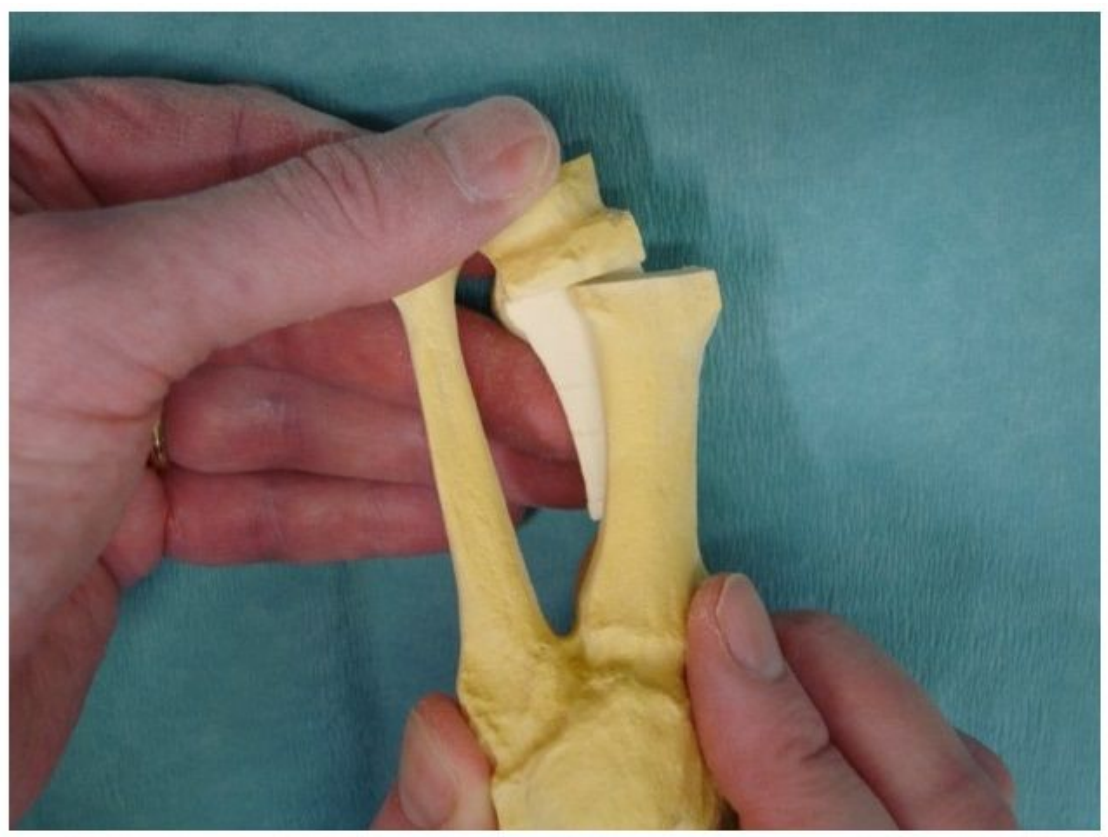

Figure 4

trotation (saw bone)

\section{Supplementary Files}

This is a list of supplementary files associated with this preprint. Click to download.

- Appendix.docx 